Published in final edited form as:

J Am Chem Soc. 2020 April 01; 142(13): 6196-6205. doi:10.1021/jacs.0c00110.

\title{
Synthesis of Met allopolymers and Direct Visualization of the Single Polymer Chain
}

\section{Zhikai Li,}

Jiangsu Key Laboratory of Advanced Functional Polymer Design and Application, State and Local Joint Engineering Laboratory for Novel Functional Polymeric Materials, College of Chemistry, Chemical Engineering and Materials Science, Soochow University, Suzhou, Jiangsu 215123, China; Department of Chemistry, University of South Florida, Tampa, Florida 33620, United States

\section{Yiming Li,}

Department of Chemistry, University of South Florida, Tampa, Florida 33620, United States

\section{Yiming Zhao,}

Jiangsu Key Laboratory of Advanced Functional Polymer Design and Application, State and Local Joint Engineering Laboratory for Novel Functional Polymeric Materials, College of Chemistry, Chemical Engineering and Materials Science, Soochow University, Suzhou, Jiangsu 215123, China

\section{Heng Wang,}

Department of Chemistry, University of South Florida, Tampa, Florida 33620, United States; College of Chemistry and Environmental Engineering, Shenzhen University, Shenzhen, Guangdong 518055, China

\section{Yuan Zhang,}

Nanoscience and Technology Division, Argonne National Laboratory, Lemont, Illinois 60439, United States; Department of Physics, Old Dominion University, Norfolk, Virginia 23529, United States

\section{Bo Song,}

Department of Chemistry, University of South Florida, Tampa, Florida 33620, United States

\section{Xiaohong Li,}

Jiangsu Key Laboratory of Advanced Functional Polymer Design and Application, State and Local Joint Engineering Laboratory for Novel Functional Polymeric Materials, College of Chemistry,

Corresponding Authors:Saw-Wai Hla - Nanoscience and Technology Division, Argonne National Laboratory, Lemont, Illinois 60439, United States; tshla@ anl.gov; Yingfeng Tu - Jiangsu Key Laboratory of Advanced Functional Polymer Design and Application, State and Local Joint Engineering Laboratory for Novel Functional Polymeric Materials, College of Chemistry, Chemical Engineering and Materials Science, Soochow University, Suzhou, Jiangsu 215123, China; tuyingfeng@ suda.edu.cn; Xiaopeng Li Department of Chemistry, University of South Florida, Tampa, Florida 33620, United States; xiaopengli1 @ usf.edu.

Author Contributions

Z.L., Y.L., and Y.Z. contributed equally to this work.

Supporting Information

The Supporting Information is available free of charge at https://pubs.acs.org/doi/10.1021/jacs.0c00110. Instrumentation, synthetic details, molecular modeling, monomer and polymer characterization, including ${ }^{1} \mathrm{H}$ NMR, ${ }^{13} \mathrm{C}$ NMR, 2D COSY, 2D NOESY, ESI-MS, UV-vis, and additional STM image (PDF) 
Chemical Engineering and Materials Science, Soochow University, Suzhou, Jiangsu 215123, China

Shuai Lu,

Department of Chemistry, University of South Florida, Tampa, Florida 33620, United States; College of Chemistry, Zhengzhou University, Zhengzhou, Henan 450001, China

Xin-Qi Hao,

College of Chemistry, Zhengzhou University, Zhengzhou, Henan 450001, China;

\section{Saw-Wai Hla,}

Nanoscience and Technology Division, Argonne National Laboratory, Lemont, Illinois 60439, United States;

\section{Yingfeng Tu,}

Jiangsu Key Laboratory of Advanced Functional Polymer Design and Application, State and Local Joint Engineering Laboratory for Novel Functional Polymeric Materials, College of Chemistry, Chemical Engineering and Materials Science, Soochow University, Suzhou, Jiangsu 215123, China;

\section{Xiaopeng Li}

Department of Chemistry, University of South Florida, Tampa, Florida 33620, United States;

\section{Abstract}

During the past few decades, the study of the single polymer chain has attracted considerable attention with the goal of exploring the structure-property relationship of polymers. It still, however, remains challenging due to the variability and low atomic resolution of the amorphous single polymer chain. Here, we demonstrated a new strategy to visualize the single metallopolymer chain with a hexameric or trimeric supramolecule as a repeat unit, in which $\mathrm{Ru}$ (II) with strong coordination and $\mathrm{Fe}(\mathrm{II})$ with weak coordination were combined together in a stepwise manner. With the help of ultrahigh-vacuum, low-temperature scanning tunneling microscopy (UHV-LT-STM) and scanning tunneling spectroscopy (STS), we were able to directly visualize both $\mathrm{Ru}(\mathrm{II})$ and $\mathrm{Fe}(\mathrm{II})$, which act as staining reagents on the repeat units, thus providing detailed structural information for the single polymer chain. As such, the direct visualization of the single random polymer chain is realized to enhance the characterization of polymers at the singlemolecule level.

\section{Graphical Abstract}




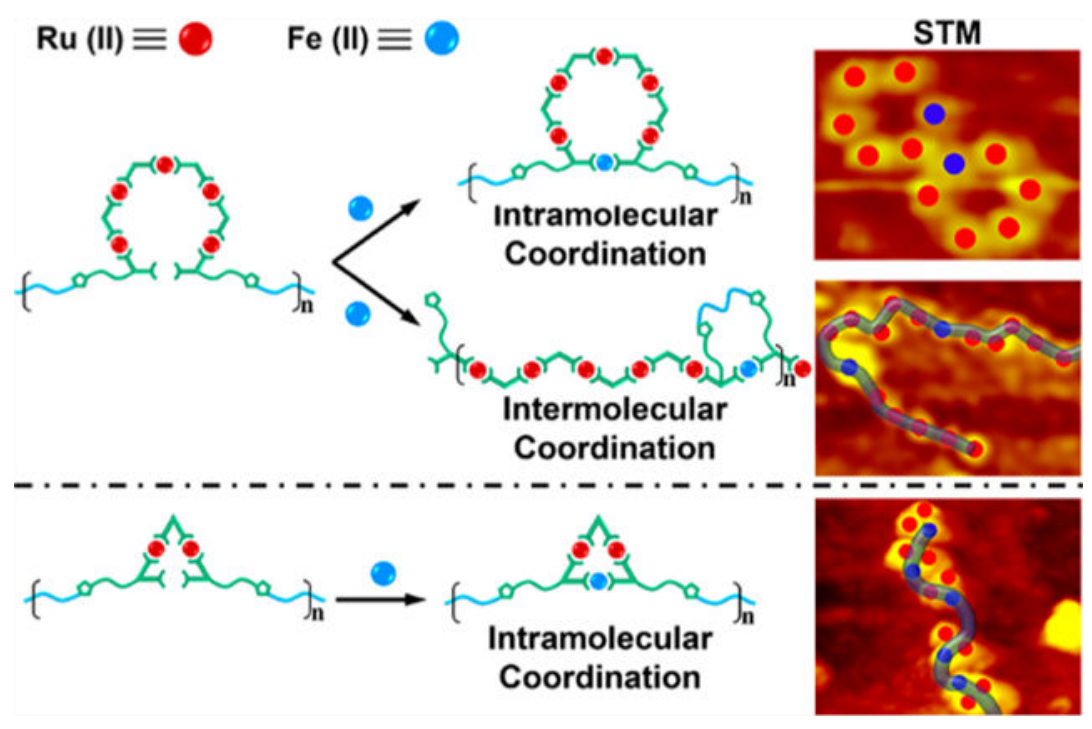

\section{INTRODUCTION}

Over the past decades, to enhance the understanding of the structure-property relationship of polymers, characterization of single polymer chain has attracted widespread attention. ${ }^{1,2}$ Microscopy, such as scanning tunneling microscopy (STM) or atomic force microscopy (AFM), allows us to observe the molecular structures directly. However, except for the large biomolecules such as DNA, ${ }^{3-7}$ the imaging of structure as well as conformation is mainly limited to crystalline, liquid crystalline, and the aggregation of polymer chains. ${ }^{8-13}$ With densely grafted side-chains, the worm-like polymer bottle-brushes can be observed directly, ${ }^{14-23}$ yet the dense and long side chains severely affect the polymeric backbone conformation. ${ }^{24,25} \mathrm{~A}$ formidable challenge still remains to address the random coil conformations of amorphous single polymer chain due to the variability and low atomic resolution.

As is known to all, metals or metal ions with high electron density can afford relatively strong signals and enhanced atomic resolution under microscopy like STM. Therefore, if one can introduce these metal components into polymer chains as "staining reagents", the amorphous single polymer chain could be easily observed and confirmed by STM depending on the position of metal. Generally, metal components are introduced into polymers through three approaches, viz., (1) polymerization of monomers with metal ions in the main chains or pendant groups, ${ }^{26-30}$ (2) supramolecular polymerization through coordination of metal ions with organic monomer in the main chains, ${ }^{31-41}$ and (3) metalation of pendant groups through postpolymerization modification. ${ }^{42-53}$ However, these approaches have certain limitations. In the first approach, the polymerization is typically centered on small and stable metal-organic components, e.g., metallocenes, which are polymerized through living radical polymerization, ring-opening metathesis polymerization (ROMP), and so on. ${ }^{54-56}$ In the second approach, the supramolecular polymerization is mainly achieved through dynamic coordination interaction. ${ }^{32,36,37,39-41,57}$ Therefore, precise control of the polymerization is difficult for dynamic supramolecular polymers with labile coordination bonds. In the third 
approach, metalation of pendant groups after polymerization is also limited to metal with weak coordination to get low-defect polymers. ${ }^{42,44-48}$ To date, very few systems were able to harness both strong and weak coordination metal ions together into metallopolymers with discrete supra-molecules as repeat units.

Thanks to the recent flourish of 2D and 3D metallosupramolecular structures with precisely controlled sizes and shapes constructed by coordination-driven self-assembly, ${ }^{58-82}$ we introduced two discrete structures, hexameric and trimeric metallosupramolecules, as repeat units to construct metallopolymers due to the high symmetry as well as the appropriate size for STM imaging (Scheme 1). The copper(I)-catalyzed azide-alkyne cycloaddition (CuAAC) "click" reaction, which owns the advantages of fast reaction rates and high yields with mild reaction conditions, ${ }^{83-86}$ was selected for the polymerization. In this design, we bridged the $2,2^{\prime}: 6^{\prime}, 2^{\prime \prime}$-terpyridine (tpy) ligand and $\mathrm{Ru}(\mathrm{II})$ with strong coordination interaction to create the open-form metal-organic hexameric and trimeric monomers with free tpy.

After polymerization by the click reaction, through further metalation of $\mathrm{Fe}(\mathrm{II})$ with weak coordination, both strong and weak binding metal ions were harnessed into one polymer system in a stepwise manner. Our initial assumption was that the metalation of Fe(II) of metal-organic monomers would form the ring-closing hexagon or triangle as repeat units, and we could measure the structure and conformation of the amorphous single polymer chain based on the location of $\mathrm{Ru}(\mathrm{II})$ and $\mathrm{Fe}(\mathrm{II})$. Unexpectedly, according to the results of ultrahigh-vacuum, low-temperature scanning tunneling microscopy (UHV-LT-STM) and scanning tunneling spectroscopy (STS), both the hexagon assembled by intramolecular coordination and linear chains assembled by intermolecular assembly were observed. In contrast, only the intramolecular assembly into the triangle existed in trimeric repeat units.

\section{RESULTS AND DISCUSSION}

Scheme 1 depicts the two metal-organic monomers with open-form structures, viz., hexameric monomer (Hex-M) and trimeric monomer (Tri-M), which were prepared according to the procedure as shown in the Supporting Information (Schemes S1-S5 and Figures S1-S76). Briefly, Hex-M was synthesized through a well-established stepwise strategy based on the strong connectivity of $\langle$ tpy-Ru(II)-tpy $\rangle,{ }^{87-94}$ by which six ditopic tpy ligands bearing a $120^{\circ}$ angle were bridged linearly with five $\mathrm{Ru}(\mathrm{II})$ ions. Similarly, two $\mathrm{Ru}(\mathrm{II})$ ions were used to bridge three ditopic tpy ligands with $60^{\circ}$ angle together to afford Tri-M. Note that Hex-M and Tri-M are functionalized by dual azide groups, which were designed for the next polymerization by click reaction. The ${ }^{1} \mathrm{H}$ NMR spectra of Hex-M and Tri-M are shown in Figures 1A and 1E, with proton labeling at the top of Scheme 1. The assignment of peaks associated with the chemical structure was assisted by the twodimensional (2D) ${ }^{1} \mathrm{H}-{ }^{1} \mathrm{H}$ gCOSY and NOESY NMR spectra (Figures S41-S44 and S71S74). After treating the precursors (compounds 8 and 16) bearing chloride as terminal groups with sodium azide, the triplet peak for the methylene unit near chloride at around $3.59 \mathrm{ppm}$ totally disappeared with a new triplet peak at $3.28 \mathrm{ppm}$ appearing, demonstrating that the conversion was completed. The integrals from corresponding peaks fit well with the theoretical value, indicating the high purity of Hex-M and Tri-M. 
The Hex-M and Tri-M monomers were further characterized by electrospray ionizationmass spectrometry (ESIMS). Hex-M (Figure 2A) was observed with a dominant set of peaks with continuous charge states from $6+$ to $10+$ due to successive loss of the counterions, $\mathrm{PF}^{-}$ 6. The experimental isotope pattern of each charge state agrees well with its theoretical simulation result (inset and Figure S46). The averaged molecular mass is deconvoluted as $7019 \mathrm{Da}$, which matches the chemical composition $\left[\mathrm{C}_{340} \mathrm{H}_{294} \mathrm{~N}_{42} \mathrm{O}_{6} \mathrm{Ru}_{5} \mathrm{P}_{10} \mathrm{~F}_{60}\right]$. Figure $2 \mathrm{C}$ shows the ESI-MS of Tri-M with continuous charge states from 3+ to 4+. The experimental isotope pattern of each charge state is also consistent with the simulated one (inset and Figure S76). The averaged molecular mass is deconvoluted as $3375 \mathrm{Da}$, which has a good agreement with the chemical composition $\left[\mathrm{C}_{168} \mathrm{H}_{142} \mathrm{~N}_{24} \mathrm{O}_{6} \mathrm{Ru}_{2} \mathrm{P}_{4} \mathrm{~F}_{24}\right]$. Furthermore, traveling wave ion mobility-mass spectrometry (TWIM-MS) spectra (Figure 2B,D) show a series of narrowly distributed signals with successive charge states for both Hex-M and Tri$\mathbf{M}$, indicating high isomeric purity of the structures.

Alkyne-terminated pentaethylene glycol (Alkyne-PEG, Scheme S6 and Figures S77-S79) was selected as another component to polymerize with the monomers (Hex-M and Tri-M) to construct the corresponding metallopolymers (Hex-P and Tri-P) by the click reaction (Scheme S7). During the polymerization process in DMF, a large amount of precipitation was produced, suggesting the formation of metallopolymers (Hex-P and Tri-P). The products were fully characterized by NMR and matrix-assisted laser desorption ionization time-of-flight (MALDI-TOF). Figure 1 shows the ${ }^{1} \mathrm{H}$ NMR spectra of Hex-P (Figure 1B) and Tri-P (Figure 1D), while 2D ${ }^{1} \mathrm{H}-{ }^{1} \mathrm{H}$ gCOSY and NOESY NMR spectra are provided in the Supporting Information (Figures S80-S89). The triplet peak at $3.28 \mathrm{ppm}$ corresponding to a methylene unit near the azide group of the monomers (Hex-M and Tri-M) disappeared, indicating monomers were completely reacted. After the formation of triazole by click reaction, this triplet peak was significantly shifted downfield $(\sim 1.23 \mathrm{ppm})$ and the protons of alkynyl group were dramatically shifted downfield ( 4.99 ppm).

Because of the strong electrostatic interactions between charged polymer backbones and counterions, the characterization data by size exclusion chromatography, viscometry, and laser light scattering may come from the associations rather than the single chains of the metallopolymers, which can be regarded as a kind of polyelectrolyte. Because all the solution-based techniques have the similar problem, MALDI-TOF mass spectrometry was further used to characterize the metallopolymers with open-form monomers in their solid states. In contrast to losing multiple counterions for ESI-MS of monomers, such metallopolymers are mainly ionized by losing a single counterion, that is, $\mathrm{PF}_{6}{ }^{-}$in this study. Hex-P (Figure 3A) shows a series of peaks with an interval of ca. $7340 \mathrm{Da}$, in good agreement with the molar mass of the repeat unit in Hex-P (Hex-M with Alkyne-PEG, $\mathrm{C}_{356} \mathrm{H}_{320} \mathrm{~N}_{42} \mathrm{O}_{12} \mathrm{Ru}_{5} \mathrm{P}_{10} \mathrm{~F}_{60}$; theoretical value: $7334 \mathrm{Da}$ ). A high molecular weight signal up to $73400(\mathrm{~m} / \mathrm{z})$ was detected with the degree of polymerization of 10 , directly confirming the successful synthesis of the corresponding metallopolymer Hex-P. In terms of polymers with a large polydispersity index value (PDI), it is worth noting that MALDI-TOF generally displays a nonsymmetrical distribution of peaks for polymers with higher abundant signals at low $\mathrm{m} / \mathrm{z}$ range due to the high ionization efficiency of species with low molecular weight. 95-97 This also suggested that large oligomers with a high polymerization degree might exist 
in our system; however, they were not ionized due to the limitation of MALDI-TOF. With small monomer Tri-M, a much higher degree of polymerization was detected in Tri-P as shown in Figure 3B. A high molecular weight signal up to $70000(\mathrm{~m} / \mathrm{z})$ was obtained with the degree of polymerization of 19 , indicating the successful synthesis of corresponding metallopolymer Tri-P. The average interval between adjacent peaks is about $3684 \mathrm{Da}$, which agrees with the molar mass of the repeat unit in Tri-P (Tri-M with Alkyne-PEG, $\mathrm{C}_{184} \mathrm{H}_{168} \mathrm{~N}_{24} \mathrm{O}_{12} \mathrm{Ru}_{2} \mathrm{P}_{4} \mathrm{~F}_{24}$; theoretical value: $3689 \mathrm{Da}$ ).

After polymerization, $\mathrm{Fe}(\mathrm{II})$ with weak coordination was introduced for further metalation. 35,42,98-103 To avoid the undesired cross-link between different polymer chains, a low concentration $\left(0.2 \mathrm{mg} \mathrm{mL}^{-1}\right)$ of metallopolymers (Hex-P and Tri-P) was used in the metalation process. The metalation results were supported by the ultraviolet-visible (UVvis) absorption spectra as shown in Figure S90. In both metallopolymers, the expected peak at about $496 \mathrm{~nm}$ was ascribed to the metal-to-ligand charge-transfer transition (MLCT) of $\langle$ tpy-Ru(II)-tpy $\rangle$ connectivity. ${ }^{31,101,104}$ After Fe(II) was introduced, a new emerging peak at about $574 \mathrm{~nm}$ that was attributed to the characteristic MLCT band of the 〈tpy-Fe(II)-tpy was observed, indicating successful metalation. ${ }^{35,98,99,101-104}$

Furthermore, ultrahigh-vacuum, low-temperature scanning tunneling microscopy (UHV-LTSTM) was then used in an effort to characterize metallopolymers and address the structure and conformation of polymer chains. Samples were dissolved in acetonitrile and deposited on an $\mathrm{Ag}$ (111) surface by drop-casting. It should be noted that to clearly observe a single metallopolymer chain, a low concentration $\left(0.05 \mathrm{mg} \mathrm{mL}^{-1}\right)$ was used to prepare the STM sample. Because of the octahedral coordination geometry and higher electron density around the metal ions, the $\langle$ tpy-Ru(II)-tpy $\rangle$ or $\langle$ tpy-Fe(II)-tpy $\rangle$ units as the stained spots gave rise to a relatively strong signal in the form of a bright lobe when compared to the organic portions. 105

Figure 4A and Figure S92 show the STM images of Hex-P, in which each of the five bright lobes located closely together correspond to five connected $\langle$ tpy-Ru(II)-tpy $\rangle$ units, indicating the successful formation of metallopolymers. Aggregation occurred due to the poor solubility of Hex-P in acetonitrile, making it difficult to observe longer polymer chains, and only large bright spots are observed for aggregates as shown in Figure S92. We also used DMF and DMSO as solvents, which however caused severe background signals during UHV-LTSTM imaging. After self-assembly with Fe(II), six bright lobes including five $\langle$ tpy$\mathrm{Ru}$ (II)-tpy $\rangle$ units and one $\langle$ tpy-Fe(II)-tpy $\rangle$ unit are observed as a group (Figure $4 \mathrm{C}$ and Figure S93). As expected, the repeat units of Hex-P underwent intramolecular coordination into a ring-closed structure, and six bright lobes arranged in a cyclic hexagonal structure (Hex-P-C). The distance between two adjacent bright lobes of the cyclic hexagonal structure is around $2.1 \mathrm{~nm}$, which is well consistent with the calculated size by modeling (Figure S91). Also, because of the poor solubility, we were only able to observe one metallopolymer chain with three cyclic hexagonal repeat units (Figure S93). Besides intramolecular coordination, intermolecular coordination into a linear chain (Hex-P-L) was also observed as shown in Figure 4E and Figure S93. It should originate from the constraint of the repeat units in the metallopolymer chain, where Alkyne-PEG brings two monomers close enough for the occurrence of intermolecular complexation. 
The positions of $\mathrm{Fe}(\mathrm{II})$ and $\mathrm{Ru}$ (II) ions in the repeat units were identified by the means of $\mathrm{d} I / \mathrm{d} V-V$ using scanning tunneling spectroscopy (STS) which probed local density of states (LDOS). ${ }^{106,107}$ Tunneling spectra were measured by positioning the STM tip above each lobe of the repeat units on the $\mathrm{Ag}$ (111) surface at a fixed height with a bias range of $\pm 2 \mathrm{~V}$. From $\mathrm{d} I / \mathrm{d} V-V$ spectroscopic data, the energy gap between the HOMO and LUMO can be directly obtained. ${ }^{108}$ Thus, from the STS measurements of each $\langle$ tpy-metal(II)-tpy $\rangle$ unit, we were able to differentiate the $\mathrm{Fe}$ (II) and $\mathrm{Ru}$ (II) centers based on their different energy gaps. Among the six bright lobes of a group, one bright lobe in each group in Figure 4C,E gives the HOMO-LUMO gap of $2.4 \mathrm{eV}$ (Figure 4H), while the remaining five bright lobes provide the gap value of $2.8 \mathrm{eV}$ (Figure 4G). Thus, we can identify the site with a smaller gap, viz. $2.4 \mathrm{eV}$, as $\mathrm{Fe}$ (II) and that of the larger gap, viz. $2.8 \mathrm{eV}$, as the Ru(II) site. Then, STM imaging was able to directly read the "sequence" of metal ion within the polymer chains (Figure 4D,F), in which red and blue dots represent the $\langle$ tpy-Ru(II)-tpy $\rangle$ and $\langle$ tpy-Fe(II)-tpy $\rangle$ units, respectively. More importantly, the polymer chain can be profiled depending on the positions of metal ions as shown in Figure 4F, by which we were able to deduce the conformation of the polymer chain.

In the STM image of Tri-P, each of the two bright lobes positioning closely together represents two connected $\langle$ tpy-Ru(II)-tpy $\rangle$ within a repeat unit (Figure 5A and Figure S94). With the introduction of Fe(II), all of the repeat units performed intramolecular coordination to form a ring-closing structure, where three bright lobes arranged into a triangle (Tri-P-C) as evidenced by STM imaging (Figure 5C and Figure S95). The distance between two adjacent bright lobes of the cyclic triangular structure is ca. $1.2 \mathrm{~nm}$, which is well consistent with the modeling size (Figure S91). It should be noted that with enhanced solubility up to 12 triangular repeat units were observed in a single polymer chain, much higher than that in the hexameric system. This result is consistent with the MALDI-TOF MS data as shown in Figure 3. The positions of $\mathrm{Fe}(\mathrm{II})$ and $\mathrm{Ru}$ (II) ions in the repeat unit are also identified by the means of $\mathrm{d} I / \mathrm{d} V-V$ obtained in STS (Figure 5E,F). We then labeled the $\langle$ tpy-Ru(II)-tpy $\rangle$ and $\langle$ tpy-Fe(II)-tpy $\rangle$ units with red and blue dots, respectively, on the basis of STS results (Figure 5B,D). The polymer chain is readily profiled by using the blue dots because all 〈tpy$\mathrm{Fe}(\mathrm{II})$-tpy $\rangle$ units are located right in the middle of the chain. Meanwhile, the conformation could be estimated and proposed according to the polymer chain drawn as shown in the inset of Figure 5D. It should be noted that theoretically the molecular weight and polydispersity index for the metallopolymers can be calculated based on the observed polymer single chains from STM images. However, to obtain a statistically average value, hundreds of highresolution STM images without strong aggregation are needed, which is not practical currently.

\section{CONCLUSIONS}

In summary, a novel class of metallopolymers were synthesized by harnessing Ru(II) with strong interaction and $\mathrm{Fe}$ (II) with weak interaction into one polymer system in a stepwise manner. First, open-form metal-organic monomers with $\mathrm{Ru}(\mathrm{II})$ were polymerized by click reaction to form the corresponding metallopolymers (Hex-P and Tri-P). After further metalation by Fe(II), Hex-P and Tri-P displayed different coordinations or self-assembly behaviors. More importantly, the structures and conformations of single polymer chains can 
be directly visualized through STM and STS of the $\langle$ tpy-metal(II)-tpy $\rangle$ units. The metallopolymers generated by Hex-P include not only hexagons constructed by intramolecular coordination but also hexameric linear chains formed by intermolecular coordination. In a sharp contrast, the further coordination of Tri-P was performed in a more controlled manner with only intramolecular complexation observed to form triangles as the repeat units. The different results are attributed to the size and rigidity of the repeat units. Overall, our endeavors will bring innovative aspects into polymer chemistry field and shed light on the development of innovative approaches to synthesize metallopolymers and study the structure and conformation of polymer chains at the single-molecule level. The characterization with the combination of STM and STS could be expanded into other metallopolymer systems to advance our understanding of the structure-property relationship of polymers.

\section{Supplementary Material}

Refer to Web version on PubMed Central for supplementary material.

\section{ACKNOWLEDGMENTS}

We acknowledge the support from National Institutes of Health (R01GM128037 to X.L.) and National Science Foundation of China (21774090 to Y.T.). Use of the Center for Nanoscale Materials, an Office of Science user facility, was supported by the U.S. Department of Energy, Office of Science, Office of Basic Energy Sciences, under Contract DEAC02-06CH11357. We also acknowledge partial support through University of South Florida Nexus Initiative (UNI) Award and the Priority Academic Program Development of Jiangsu Higher Education Institutions (PAPD).

\section{REFERENCES}

(1). Kumaki J; Sakurai S.-i.; Yashima E Visualization of Synthetic Helical Polymers by HighResolution Atomic Force Microscopy. Chem. Soc. Rev 2009, 38, 737-746. [PubMed: 19322466]

(2). Ouchi M; Badi N; Lutz J-F; Sawamoto M Single-Chain Technology Using Discrete Synthetic Macromolecules. Nat. Chem 2011, 3, 917-924. [PubMed: 22109270]

(3). Hansma HG; Vesenka J; Siegerist C; Kelderman G; Morrett H; Sinsheimer RL; Elings V; Bustamante C; Hansma PK Reproducible Imaging and Dissection of Plasmid DNA Under Liquid with the Atomic Force Microscope. Science 1992, 256, 1180-1184. [PubMed: 1589799]

(4). Guckenberger R; Heim M; Cevc G; Knapp H; Wiegräbe W; Hillebrand A Scanning Tunneling Microscopy of Insulators and Biological Specimens Based on Lateral Conductivity of Ultrathin Water Films. Science 1994, 266, 1538-1540. [PubMed: 7985024]

(5). Adamcik J; Klinov DV; Witz G; Sekatskii SK; Dietler G Observation of Single-Stranded DNA on Mica and Highly Oriented Pyrolytic Graphite by Atomic Force Microscopy. FEBS Lett 2006, 580, 5671-5675. [PubMed: 17007844]

(6). Leung C; Bestembayeva A; Thorogate R; Stinson J; Pyne A; Marcovich C; Yang J; Drechsler U; Despont M; Jankowski T; Tschöpe M; Hoogenboom BW Atomic Force Microscopy with Nanoscale Cantilevers Resolves Different Structural Conformations of the DNA Double Helix. Nano Lett 2012, 12, 3846-3850. [PubMed: 22731615]

(7). Terasaki K; Yokoyama T Structural Modification of DNA Studied by Scanning Tunneling Microscopy. J. Phys. Chem. B 2019, 123, 1780-1783. [PubMed: 30721062]

(8). Abe H; Kikkawa Y; Iwata T; Aoki H; Akehata T; Doi Y Microscopic Visualization on Crystalline Morphologies of Thin Films for Poly[(R)-3-hydroxybutyric acid] and Its Copolymer. Polymer 2000, 41, 867-874. 
(9). Reiter G; Castelein G; Sommer J-U; Röttele A; Thurn-Albrecht T Direct Visualization of Random Crystallization and Melting in Arrays of Nanometer-Size Polymer Crystals. Phys. Rev. Lett 2001, 87, 226101. [PubMed: 11736411]

(10). Banno M; Wu Z-Q; Nagai K; Sakurai S.-i.; Okoshi K; Yashima E Two-Dimensional Bilayer Smectic Ordering of Rigid Rod-Rod Helical Diblock Polyisocyanides. Macromolecules 2010, 43, 6553-6561.

(11). Kumaki J; Kajitani T; Nagai K; Okoshi K; Yashima E Visualization of Polymer Chain Conformations in Amorphous Polyisocyanide Langmuir-Blodgett Films by Atomic Force Microscopy. J. Am. Chem. Soc 2010, 132, 5604-5606. [PubMed: 20356310]

(12). Banno M; Yamaguchi T; Nagai K; Kaiser C; Hecht S; Yashima E Optically Active, Amphiphilic Poly(meta-phenylene ethynylene)s: Synthesis, Hydrogen-Bonding Enforced Helix Stability, and Direct AFM Observation of Their Helical Structures. J. Am. Chem. Soc 2012, 134, 8718-8728. [PubMed: 22540863]

(13). Guan W; Wang G; Ding J; Li B; Wu L A Supramolecular Approach of Modified Polyoxometalate Polymerization and Visualization of a Single Polymer Chain. Chem. Commun 2019, 55, 10788-10791.

(14). Schappacher M; Deffieux A Synthesis of Macrocyclic Copolymer Brushes and Their SelfAssembly into Supramolecular Tubes. Science 2008, 319, 1512-1515. [PubMed: 18339934]

(15). Sheiko SS; Sumerlin BS; Matyjaszewski K Cylindrical Molecular Brushes: Synthesis, Characterization, and Properties. Prog. Polym. Sci 2008, 33, 759-785.

(16). Yuan J; Xu Y; Walther A; Bolisetty S; Schumacher M; Schmalz H; Ballauff M; Müller AHE Water-Soluble Organo-Silica Hybrid Nanowires. Nat. Mater 2008, 7, 718-722. [PubMed: 18641655]

(17). Rzayev J Synthesis of Polystyrene-Polylactide Bottlebrush Block Copolymers and Their Melt Self-Assembly into Large Domain Nanostructures. Macromolecules 2009, 42, 2135-2141.

(18). Lee H.-i.; Pietrasik J; Sheiko SS; Matyjaszewski K Stimuli-Responsive Molecular Brushes. Prog. Polym. Sci 2010, 35, 24-44.

(19). Nese A; Kwak Y; Nicolaÿ R; Barrett M; Sheiko SS; Matyjaszewski K Synthesis of Poly(vinyl acetate) Molecular Brushes by a Combination of Atom Transfer Radical Polymerization (ATRP) and Reversible Addition-Fragmentation Chain Transfer (RAFT) Polymerization. Macromolecules 2010, 43, 4016-4019.

(20). Feng C; Li Y; Yang D; Hu J; Zhang X; Huang X Well-Defined Graft Copolymers: from Controlled Synthesis to Multi-purpose Applications. Chem. Soc. Rev 2011, 40, 1282-1295. [PubMed: 21107479]

(21). Nese A; Li Y; Averick S; Kwak Y; Konkolewicz D; Sheiko SS; Matyjaszewski K Synthesis of Amphiphilic Poly(N-vinylpyrrolidone)-b-poly(vinyl acetate) Molecular Bottlebrushes. ACS Macro Lett 2012, 1, 227-231.

(22). Verduzco R; Li X; Pesek SL; Stein GE Structure, Function, Self-Assembly, and Applications of Bottlebrush Copolymers. Chem. Soc. Rev 2015, 44, 2405-2420. [PubMed: 25688538]

(23). Kawamoto K; Zhong M; Gadelrab KR; Cheng L-C; Ross CA; Alexander-Katz A; Johnson JA Graft-through Synthesis and Assembly of Janus Bottlebrush Polymers from A-Branch-B Diblock Macromonomers. J. Am. Chem. Soc 2016, 138, 11501-11504. [PubMed: 27580971]

(24). Lecommandoux S; Chécot F; Borsali R; Schappacher M; Deffieux A; Brulet A; Cotton JP Effect of Dense Grafting on the Backbone Conformation of Bottlebrush Polymers: Determination of the Persistence Length in Solution. Macromolecules 2002, 35, 8878-8881.

(25). Pietrasik J; Sumerlin BS; Lee H.-i.; Gil RR; Matyjaszewski K Structural Mobility of Molecular Bottle-Brushes Investigated by NMR Relaxation Dynamics. Polymer 2007, 48, 496-501.

(26). Hailes RLN; Oliver AM; Gwyther J; Whittell GR; Manners I Polyferrocenylsilanes: Synthesis, Properties, and Applications. Chem. Soc. Rev 2016, 45, 5358-5407. [PubMed: 27348354]

(27). Yan Y; Zhang J; Ren L; Tang C Metal-Containing and Related Polymers for Biomedical Applications. Chem. Soc. Rev 2016, 45, 5232-5263. [PubMed: 26910408]

(28). Zha Y; Disabb-Miller ML; Johnson ZD; Hickner MA; Tew GN Metal-Cation-Based Anion Exchange Membranes. J. Am. Chem. Soc 2012, 134, 4493-4496. [PubMed: 22385221] 
(29). Yan X; Li S; Pollock JB; Cook TR; Chen J; Zhang Y; Ji X; Yu Y; Huang F; Stang PJ Supramolecular Polymers with Tunable Topologies via Hierarchical Coordination-Driven SelfAssembly and Hydrogen Bonding Interfaces. Proc. Natl. Acad. Sci. U. S. A 2013, 110, 1558515590. [PubMed: 24019475]

(30). Zhang M; Li S; Yan X; Zhou Z; Saha ML; Wang Y-C; Stang PJ Fluorescent Metallacycle-Cored Polymers via Covalent Linkage and Their Use as Contrast Agents for Cell Imaging. Proc. Natl. Acad. Sci. U. S. A 2016, 113, 11100-11105. [PubMed: 27647900]

(31). Kelch S; Rehahn M Synthesis and Properties in Solution of Rodlike, 2,2':6',2”-TerpyridineBased Ruthenium(II) Coordination Polymers. Macromolecules 1999, 32, 5818-5828.

(32). Beck JB; Rowan SJ Multistimuli, Multiresponsive Metallo-Supramolecular Polymers. J. Am. Chem. Soc 2003, 125, 13922-13923. [PubMed: 14611204]

(33). Dobrawa R; Würthner F Metallosupramolecular Approach toward Functional Coordination Polymers. J. Polym. Sci., Part A: Polym. Chem 2005, 43, 4981-4995.

(34). Hofmeier H; Hoogenboom R; Wouters MEL; Schubert US High Molecular Weight Supramolecular Polymers Containing Both Terpyridine Metal Complexes and Ureidopyrimidinone Quadruple Hydrogen-Bonding Units in the Main Chain. J. Am. Chem. Soc 2005, 127, 2913-2921. [PubMed: 15740127]

(35). Han FS; Higuchi M; Kurth DG Metallo-Supramolecular Polymers Based on Functionalized Bisterpyridines as Novel Electrochromic Materials. Adv. Mater 2007, 19, 3928-3931.

(36). Winter A; Friebe C; Chiper M; Hager MD; Schubert US Self-Assembly of $\pi$-Conjugated Bis(terpyridine) Ligands with Zinc(II) Ions: New Metallosupramolecular Materials for Optoelectronic Applications. J. Polym. Sci., Part A: Polym. Chem 2009, 47, 4083-4098.

(37). Burnworth M; Tang L; Kumpfer JR; Duncan AJ; Beyer FL; Fiore GL; Rowan SJ; Weder C Optically Healable Supramolecular Polymers. Nature 2011, 472, 334-337. [PubMed: 21512571]

(38). Padhy H; Sahu D; Chiang I-H; Patra D; Kekuda D; Chu C-W; Lin H-C Synthesis and Applications of Main-Chain Ru(II) Metallo-Polymers Containing Bis-Terpyridyl Ligands with Various Benzodiazole Cores for Solar Cells. J. Mater. Chem 2011, 21, 1196-1205.

(39). Miller AK; Li Z; Streletzky KA; Jamieson AM; Rowan SJ Redox-Induced Polymerisation/ Depolymerisation of Metallo-Supramolecular Polymers. Polym. Chem 2012, 3, 3132-3138.

(40). Borré E; Stumbé J-F; Bellemin-Laponnaz S; Mauro M Light-Powered Self-Healable Metallosupramolecular Soft Actuators. Angew. Chem., Int. Ed 2016, 55, 1313-1317.

(41). Yan X; Xu J-F; Cook TR; Huang F; Yang Q-Z; Tung C-H; Stang PJ Photoinduced Transformations of Stiff-Stilbene-Based Discrete Metallacycles to Metallosupramolecular Polymers. Proc. Natl. Acad. Sci. U. S. A 2014, 111, 8717-8722. [PubMed: 24889610]

(42). Bode S; Zedler L; Schacher FH; Dietzek B; Schmitt M; Popp J; Hager MD; Schubert US SelfHealing Polymer Coatings Based on Crosslinked Metallosupramolecular Copolymers. Adv. Mater 2013, 25, 1634-1638. [PubMed: 23355192]

(43). Michal BT; McKenzie BM; Felder SE; Rowan SJ Metallo-, Thermo-, and Photoresponsive Shape Memory and Actuating Liquid Crystalline Elastomers. Macromolecules 2015, 48, 3239-3246.

(44). Li C-H; Wang C; Keplinger C; Zuo J-L; Jin L; Sun Y; Zheng P; Cao Y; Lissel F; Linder C; You X-Z; Bao Z A Highly Stretchable Autonomous Self-Healing Elastomer. Nat. Chem 2016, 8, 618624. [PubMed: 27219708]

(45). Tang Z; Huang J; Guo B; Zhang L; Liu F Bioinspired Engineering of Sacrificial Metal-Ligand Bonds into Elastomers with Supramechanical Performance and Adaptive Recovery. Macromolecules 2016, 49, 1781-1789.

(46). Zhang X; Tang Z; Guo B; Zhang L Enabling Design of Advanced Elastomer with Bioinspired Metal-Oxygen Coordination. ACS Appl. Mater. Interfaces 2016, 8, 32520-32527. [PubMed: 27933856]

(47). Filippidi E; Cristiani TR; Eisenbach CD; Waite JH; Israelachvili JN; Ahn BK; Valentine MT Toughening Elastomers Using Mussel-Inspired Iron-Catechol Complexes. Science 2017, 358, 502-505. [PubMed: 29074770]

(48). Yang L; Zhang G; Zheng N; Zhao Q; Xie T A Metallosupramolecular Shape-Memory Polymer with Gradient Thermal Plasticity. Angew. Chem., Int. Ed 2017, 56, 12599-12602. 
(49). Whittell GR; Hager MD; Schubert US; Manners I Functional Soft Materials from Metallopolymers and Metallosupramolecular Polymers. Nat. Mater 2011, 10, 176-188. [PubMed: 21336298]

(50). Weng G; Thanneeru S; He J Dynamic Coordination of Eu-Iminodiacetate to Control Fluorochromic Response of Polymer Hydrogels to Multistimuli. Adv. Mater 2018, 30, 1706526.

(51). Thanneeru S; Milazzo N; Lopes A; Wei Z; Angeles-Boza AM; He J Synthetic Polymers To Promote Cooperative $\mathrm{Cu}$ Activity for $\mathrm{O}_{2}$ Activation: Poly vs Mono. J. Am. Chem. Soc 2019, 141, 4252-4256. [PubMed: 30807129]

(52). Zhou X; Wang L; Wei Z; Weng G; He J An Adaptable Tough Elastomer with Moisture-Triggered Switchable Mechanical and Fluorescent Properties. Adv. Funct. Mater 2019, 29, 1903543.

(53). Aamer KA; Tew GN Supramolecular Polymers Containing Terpyridine-Metal Complexes in the Side Chain. Macromolecules 2007, 40, 2737-2744.

(54). Gu H; Ciganda R; Gatard S; Lu F; Zhao P; Ruiz J; Astruc D On Metallocene-Containing Macromolecules and Their Applications. J. Organomet. Chem 2016, 813, 95-102.

(55). Yang P; Pageni P; Kabir MP; Zhu T; Tang C Metallocene-Containing Homopolymers and Heterobimetallic Block Copolymers via Photoinduced RAFT Polymerization. ACS Macro Lett 2016, 5, 1293-1300. [PubMed: 29276651]

(56). Sha Y; Zhang Y; Zhu T; Tan S; Cha Y; Craig SL; Tang C Ring-Closing Metathesis and RingOpening Metathesis Polymerization toward Main-Chain Ferrocene-Containing Polymers. Macromolecules 2018, 51, 9131-9139.

(57). Gu Y; Alt EA; Wang H; Li X; Willard AP; Johnson JA Photoswitching Topology in Polymer Networks with Metal-Organic Cages as Crosslinks. Nature 2018, 560, 65-69. [PubMed: 30022167]

(58). Lehn J-M From Supramolecular Chemistry towards Constitutional Dynamic Chemistry and Adaptive Chemistry. Chem. Soc. Rev 2007, 36, 151-160. [PubMed: 17264919]

(59). Forgan RS; Sauvage J-P; Stoddart JF Chemical Topology: Complex Molecular Knots, Links, and Entanglements. Chem. Rev 2011, 111, 5434-5464. [PubMed: 21692460]

(60). Chakrabarty R; Mukherjee PS; Stang PJ Supramolecular Coordination: Self-Assembly of Finite Two- and Three-Dimensional Ensembles. Chem. Rev 2011, 111, 6810-6918. [PubMed: 21863792]

(61). Cook TR; Stang PJ Recent Developments in the Preparation and Chemistry of Metallacycles and Metallacages via Coordination. Chem. Rev 2015, 115, 7001-7045. [PubMed: 25813093]

(62). Yoshizawa M; Klosterman JK; Fujita M Functional Molecular Flasks: New Properties and Reactions within Discrete, Self-Assembled Hosts. Angew. Chem., Int. Ed 2009, 48, 3418-3438.

(63). Harris K; Fujita D; Fujita M Giant Hollow $\mathrm{M}_{\mathrm{n}} \mathrm{L}_{2 n}$ Spherical Complexes: Structure, Functionalisation and Applications. Chem. Commun 2013, 49, 6703-6712.

(64). McConnell AJ; Wood CS; Neelakandan PP; Nitschke JR Stimuli-Responsive Metal-Ligand Assemblies. Chem. Rev 2015, 115, 7729-7793. [PubMed: 25880789]

(65). Zarra S; Wood DM; Roberts DA; Nitschke JR Molecular Containers in Complex Chemical Systems. Chem. Soc. Rev 2015, 44, 419-432. [PubMed: 25029235]

(66). Ayme J-F; Beves JE; Campbell CJ; Leigh DA Template Synthesis of Molecular Knots. Chem. Soc. Rev 2013, 42, 1700-1712. [PubMed: 22890502]

(67). Chakraborty S; Newkome GR Terpyridine-Based Metallosupramolecular Constructs: Tailored Monomers to Precise 2D-Motifs and 3D-Metallocages. Chem. Soc. Rev 2018, 47, 3991-4016. [PubMed: 29594272]

(68). Han M; Engelhard DM; Clever GH Self-Assembled Coordination Cages Based on BananaShaped Ligands. Chem. Soc. Rev 2014, 43, 1848-1860. [PubMed: 24504200]

(69). De S; Mahata K; Schmittel M Metal-Coordination-Driven Dynamic Heteroleptic Architectures. Chem. Soc. Rev 2010, 39, 1555-1575. [PubMed: 20419210]

(70). Saha ML; De S; Pramanik S; Schmittel M Orthogonality in Discrete Self-Assembly - Survey of Current Concepts. Chem. Soc. Rev 2013, 42, 6860-6909. [PubMed: 23756556]

(71). Qi Z; Heinrich T; Moorthy S; Schalley CA Gas-Phase Chemistry of Molecular Containers. Chem. Soc. Rev 2015, 44, 515-531. [PubMed: 24956973] 
(72). Würthner F; You C-C; Saha-Möller CR Metallosupramolecular Squares: from Structure to Function. Chem. Soc. Rev 2004, 33, 133-146. [PubMed: 15026818]

(73). Chen L-J; Yang H-B; Shionoya M Chiral Metallosupramolecular Architectures. Chem. Soc. Rev 2017, 46, 2555-2576. [PubMed: 28452389]

(74). Jin P; Dalgarno SJ; Atwood JL Mixed Metal-Organic Nanocapsules. Coord. Chem. Rev 2010, 254, 1760-1768.

(75). Leininger S; Olenyuk B; Stang PJ Self-Assembly of Discrete Cyclic Nanostructures Mediated by Transition Metals. Chem. Rev 2000, 100, 853-908. [PubMed: 11749254]

(76). Olenyuk B; Whiteford JA; Fechtenkötter A; Stang PJ Self-Assembly of Nanoscale Cuboctahedra by Coordination Chemistry. Nature 1999, 398, 796-799. [PubMed: 10235260]

(77). Sun Q-F; Iwasa J; Ogawa D; Ishido Y; Sato S; Ozeki T; Sei Y; Yamaguchi K; Fujita M SelfAssembled $\mathrm{M}_{24} \mathrm{~L}_{48}$ Polyhedra and Their Sharp Structural Switch Upon Subtle Ligand Variation. Science 2010, 328, 1144-1147. [PubMed: 20430973]

(78). Fujita D; Ueda Y; Sato S; Mizuno N; Kumasaka T; Fujita M Self-Assembly of Tetravalent Goldberg Polyhedra from 144 Small Components. Nature 2016, 540, 563-566. [PubMed: 30905932]

(79). Cook TR; Zheng Y-R; Stang PJ Metal-Organic Frameworks and Self-Assembled Supramolecular Coordination Complexes: Comparing and Contrasting the Design, Synthesis, and Functionality of Metal-Organic Materials. Chem. Rev 2013, 113, 734-777. [PubMed: 23121121]

(80). Sun Y; Chen C; Stang PJ Soft Materials with Diverse Suprastructures via the Self-Assembly of Metal-Organic Complexes. Acc. Chem. Res 2019, 52, 802-817. [PubMed: 30794371]

(81). Stang PJ; Olenyuk B Self-Assembly, Symmetry, and Molecular Architecture: Coordination as the Motif in the Rational Design of Supramolecular Metallacyclic Polygons and Polyhedra. Acc. Chem. Res 1997, 30, 502-518.

(82). Wang W; Wang Y-X; Yang H-B Supramolecular Transformations within Discrete CoordinationDriven Supramolecular Architectures. Chem. Soc. Rev 2016, 45, 2656-2693. [PubMed: 27009833]

(83). Hein JE; Fokin VV Copper-Catalyzed Azide-Alkyne Cycloaddition (CuAAC) and Beyond: New Reactivity of Copper(I) Acetylides. Chem. Soc. Rev 2010, 39, 1302-1315. [PubMed: 20309487]

(84). Liang L; Astruc D The Copper(I)-Catalyzed Alkyne-Azide Cycloaddition (CuAAC) "Click" Reaction and Its Applications. An Overview. Coord. Chem. Rev 2011, 255, 2933-2945.

(85). Li Y; Zhou C; Xu L; Yao F; Cen L; Fu GD Stimuli-Responsive Hydrogels Prepared by Simultaneous "Click Chemistry" and Metal-Ligand Coordination. RSC Adv 2015, 5, 18242 18251.

(86). Singh MS; Chowdhury S; Koley S Advances of Azide-Alkyne Cycloaddition-Click Chemistry over the Recent Decade. Tetrahedron 2016, 72, 5257-5283.

(87). Newkome GR; Wang P; Moorefield CN; Cho TJ; Mohapatra PP; Li S; Hwang S-H; Lukoyanova O; Echegoyen L; Palagallo JA; Iancu V; Hla S-W Nanoassembly of a Fractal Polymer: A Molecular "Sierpinski Hexagonal Gasket. Science 2006, 312, 1782-1785. [PubMed: 16690820]

(88). Granzhan A; Schouwey C; Riis-Johannessen T; Scopelliti R; Severin K Connection of Metallamacrocycles via Dynamic Covalent Chemistry: A Versatile Method for the Synthesis of Molecular Cages. J. Am. Chem. Soc 2011, 133, 7106-7115. [PubMed: 21495636]

(89). Li K; Zhang L-Y; Yan C; Wei S-C; Pan M; Zhang L; Su C-Y Stepwise Assembly of Pd 6 (RuL3) 8 Nanoscale Rhombododecahedral Metal-Organic Cages via Metalloligand Strategy for Guest Trapping and Protection. J. Am. Chem. Soc 2014, 136, 4456-4459. [PubMed: 24611560]

(90). Lu X; Li X; Guo K; Xie T-Z; Moorefield CN; Wesdemiotis C; Newkome GR Probing a Hidden World of Molecular Self-Assembly: Concentration-Dependent, Three-Dimensional Supramolecular Interconversions. J. Am. Chem. Soc 2014, 136, 18149-18155. [PubMed: 25470035]

(91). Newkome GR; Moorefield CN From $1 \rightarrow 3$ Dendritic Designs to Fractal Supramacromolecular Constructs: Understanding the Pathway to the Sierpiński Gasket. Chem. Soc. Rev 2015, 44, 3954-3967. [PubMed: 25316287] 
(92). Li Y; Jiang Z; Wang M; Yuan J; Liu D; Yang X; Chen M; Yan J; Li X; Wang P Giant, Hollow 2D Metalloarchitecture: Stepwise Self-Assembly of a Hexagonal Supramolecular Nut. J. Am. Chem. Soc 2016, 138, 10041-10046. [PubMed: 27447878]

(93). Jiang Z; Li Y; Wang M; Liu D; Yuan J; Chen M; Wang J; Newkome GR; Sun W; Li X; Wang P Constructing High-Generation Sierpiński Triangles by Molecular Puzzling. Angew. Chem., Int. Ed 2017, 56, 11450-11455.

(94). Zhang Z; Wang H; Wang X; Li Y; Song B; Bolarinwa O; Reese RA; Zhang T; Wang X-Q; Cai J; Xu B; Wang M; Liu C; Yang H-B; Li X Supersnowflakes: Stepwise Self-Assembly and Dynamic Exchange of Rhombus Star-Shaped Supramolecules. J. Am. Chem. Soc 2017, 139, 8174-8185. [PubMed: 28558196]

(95). Schmatloch S; van den Berg AMJ; Alexeev AS; Hofmeier H; Schubert US Soluble HighMolecular-Mass Poly-(ethylene oxide)s via Self-Organization. Macromolecules 2003, 36, $9943-$ 9949.

(96). Montaudo G; Samperi F; Montaudo MS Characterization of Synthetic Polymers by MALDI-MS. Prog. Polym. Sci 2006, 31, 277-357.

(97). Li Z; Gu J; Qi S; Wu D; Gao L; Chen Z; Guo J; Li X; Wang Y; Yang X; Tu Y Shackling Effect Induced Property Differences in Metallo-Supramolecular Polymers. J. Am. Chem. Soc 2017, 139, 14364-14367. [PubMed: 28985069]

(98). Hofmeier H; Schubert US Supramolecular Branching and Crosslinking of Terpyridine-Modified Copolymers: Complexation and Decomplexation Studies in Diluted Solution. Macromol. Chem. Phys 2003, 204, 1391-1397.

(99). Beck JB; Ineman JM; Rowan SJ Metal/Ligand-Induced Formation of Metallo-Supramolecular Polymers. Macromolecules 2005, 38, 5060-5068.

(100). Knapton D; Rowan SJ; Weder C Synthesis and Properties of Metallo-Supramolecular Poly(pphenylene ethynylene)s. Macromolecules 2006, 39, 651-657.

(101). Hu C-W; Sato T; Zhang J; Moriyama S; Higuchi M Multi-Colour Electrochromic Properties of Fe/Ru-Based Bimetallo-Supramolecular Polymers. J. Mater. Chem. C 2013, 1, 3408-3413.

(102). Gao L; Zhang Z; Zheng B; Huang F Construction of Muscle-Like Metallo-Supramolecular Polymers from a Pillar[5]Arene-Based [c2]Daisy Chain. Polym. Chem 2014, 5, 5734-5739.

(103). Hu C-W; Sato T; Zhang J; Moriyama S; Higuchi M Three-Dimensional Fe(II)-based MetalloSupramolecular Polymers with Electrochromic Properties of Quick Switching, Large Contrast, and High Coloration Efficiency. ACS Appl. Mater. Interfaces 2014, 6, 9118-9125. [PubMed: 24840579]

(104). Li Y; Jiang Z; Yuan J; Liu D; Wu T; Moorefield CN; Newkome GR; Wang P Facile Thermodynamic Conversion of a Linear Metallopolymer into a Self-Assembled Hexameric Metal-lomacrocycle. Chem. Commun 2015, 51, 5766-5769.

(105). Wang H; Li Y; Yu H; Song B; Lu S; Hao X-Q; Zhang Y; Wang M; Hla S-W; Li X Combining Synthesis and Self-Assembly in One Pot To Construct Complex 2D Metallo-Supra-molecules Using Terpyridine and Pyrylium Salts. J. Am. Chem. Soc 2019, 141, 13187-13195. [PubMed: 31345024]

(106). Hasegawa Y; Avouris P Direct Observation of Standing Wave Formation at Surface Steps Using STS. Phys. Rev. Lett 1993, 71, 1071-1074. [PubMed: 10055441]

(107). Yan C; Ma D-L; Qiao J-B; Zhong H-Y; Yang L; Li S-Y; Fu Z-Q; Zhang Y; He L Scanning Tunneling Microscopy Study of the Quasicrystalline 30 Twisted Bilayer Graphene. 2D Mater 2019, 6, No. 045041.

(108). Hess HF; Robinson RB; Dynes RC; Valles JM; Waszczak JV Scanning-Tunneling-Microscope Observation of the Abrikosov Flux Lattice and the Density of States near and inside a Fluxoid. Phys. Rev. Lett 1989, 62, 214-216. [PubMed: 10039952] 
A

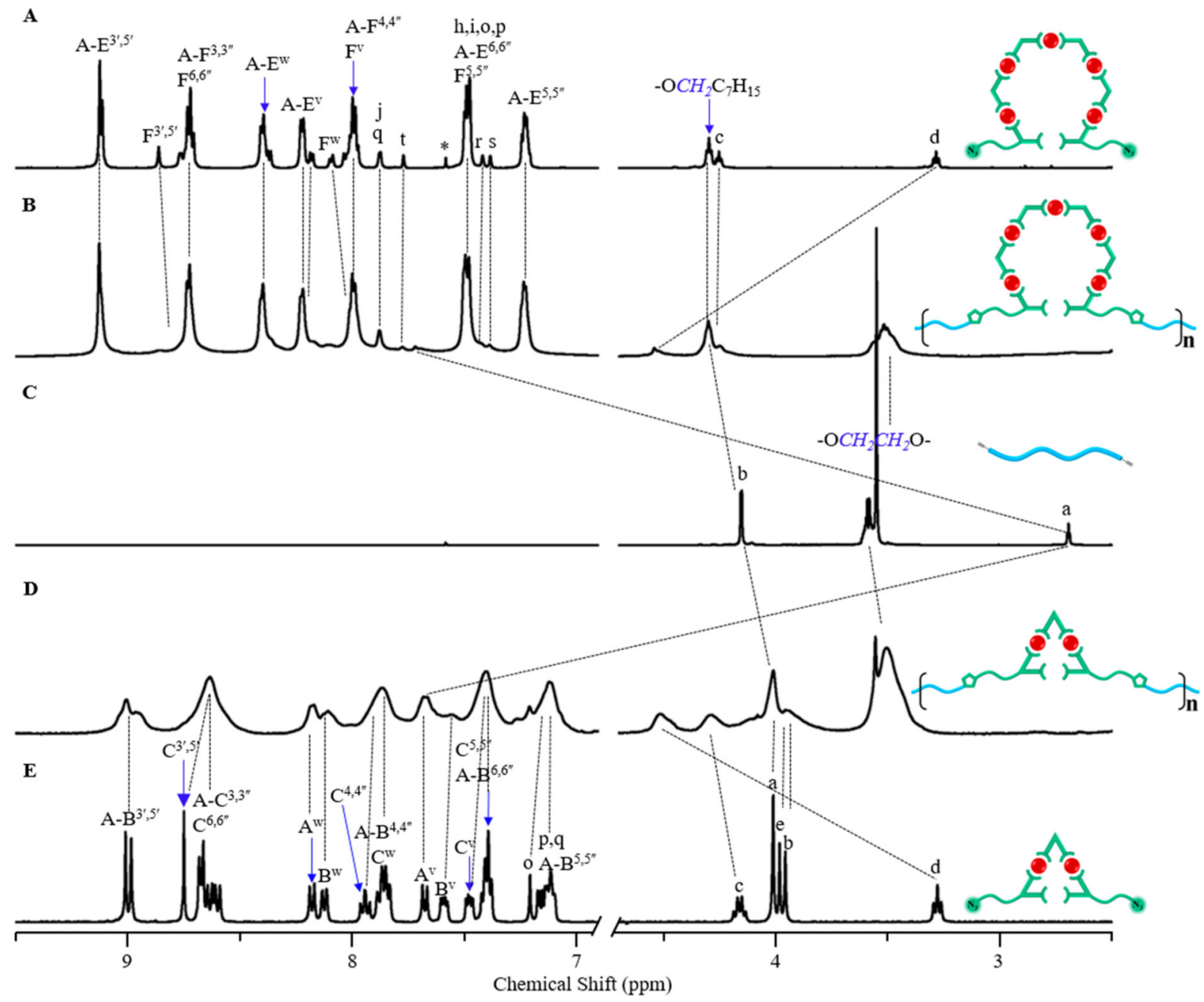

Figure 1.

${ }^{1}$ H NMR spectra of (A) Hex-M (600 MHz), (B) Hex-P (600 MHz), (C) Alkyne-PEG (400 $\mathrm{MHz}$ ), (D) Tri-P (400 MHz), and (E) Tri-M (400 MHz) in $\mathrm{CD}_{3} \mathrm{CN}$. The asterisk (*) represents the residue solvent $\mathrm{CHCl}_{3}$. 


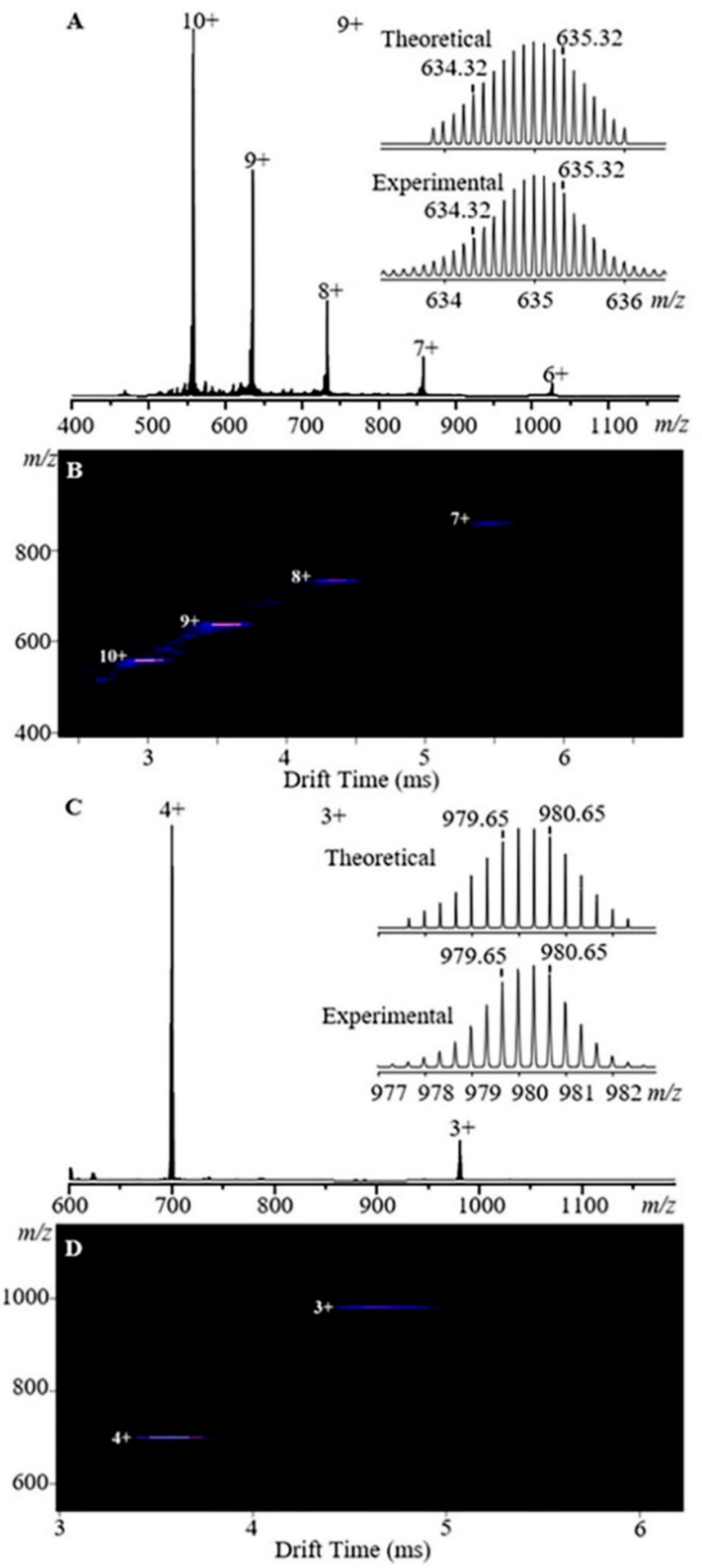

Figure 2.

ESI-MS of Hex-M (A), TWIM-MS plot ( $\mathrm{m} / z$ vs drift time) of Hex-M (B), ESI-MS of Tri$\mathbf{M}(\mathrm{C})$, and TWIM-MS plot of Tri-M (D). 

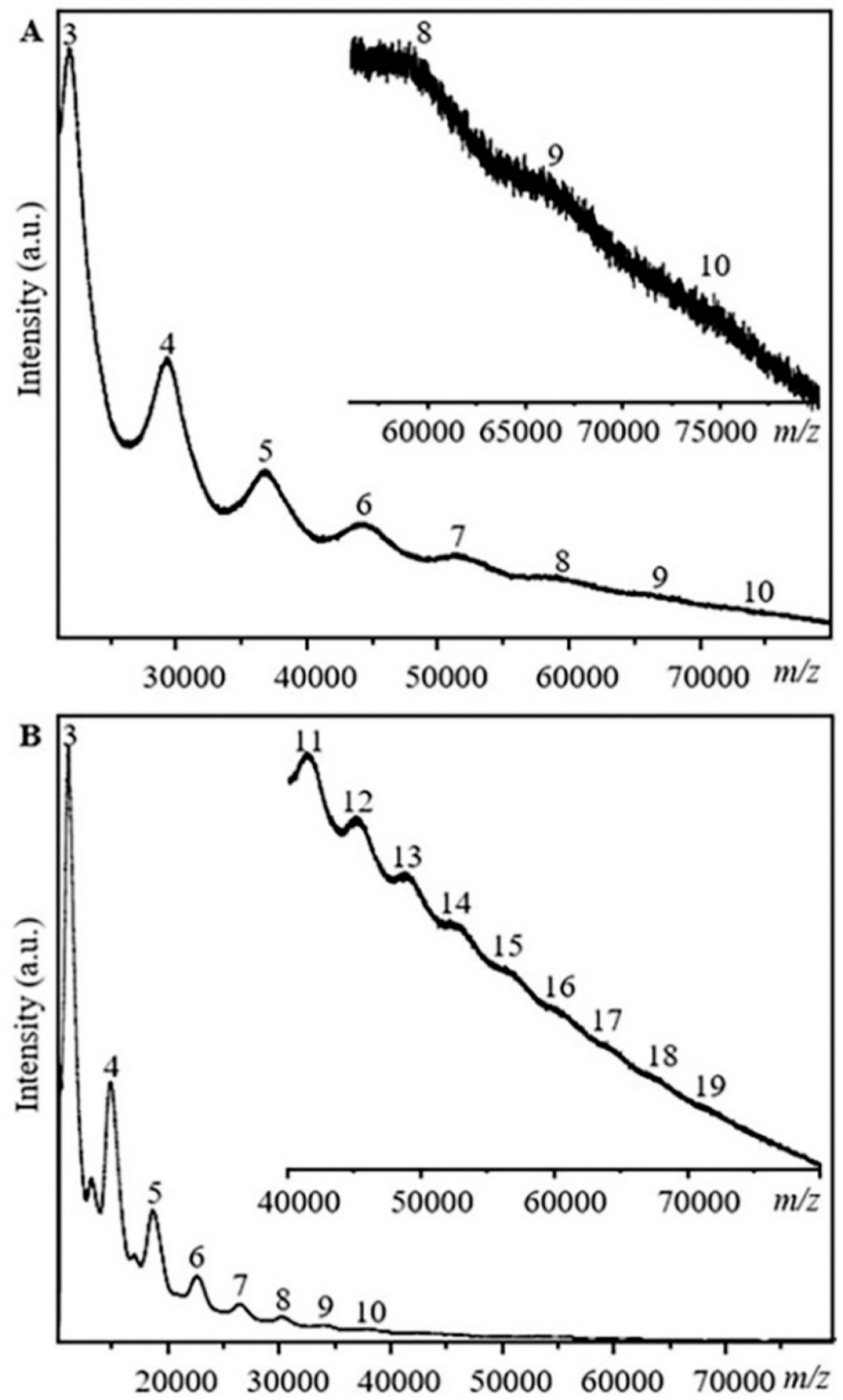

Figure 3.

MALDI-TOF MS of Hex-P (A) and Tri-P (B) with corresponding numbers of repeat units in linear mode. 

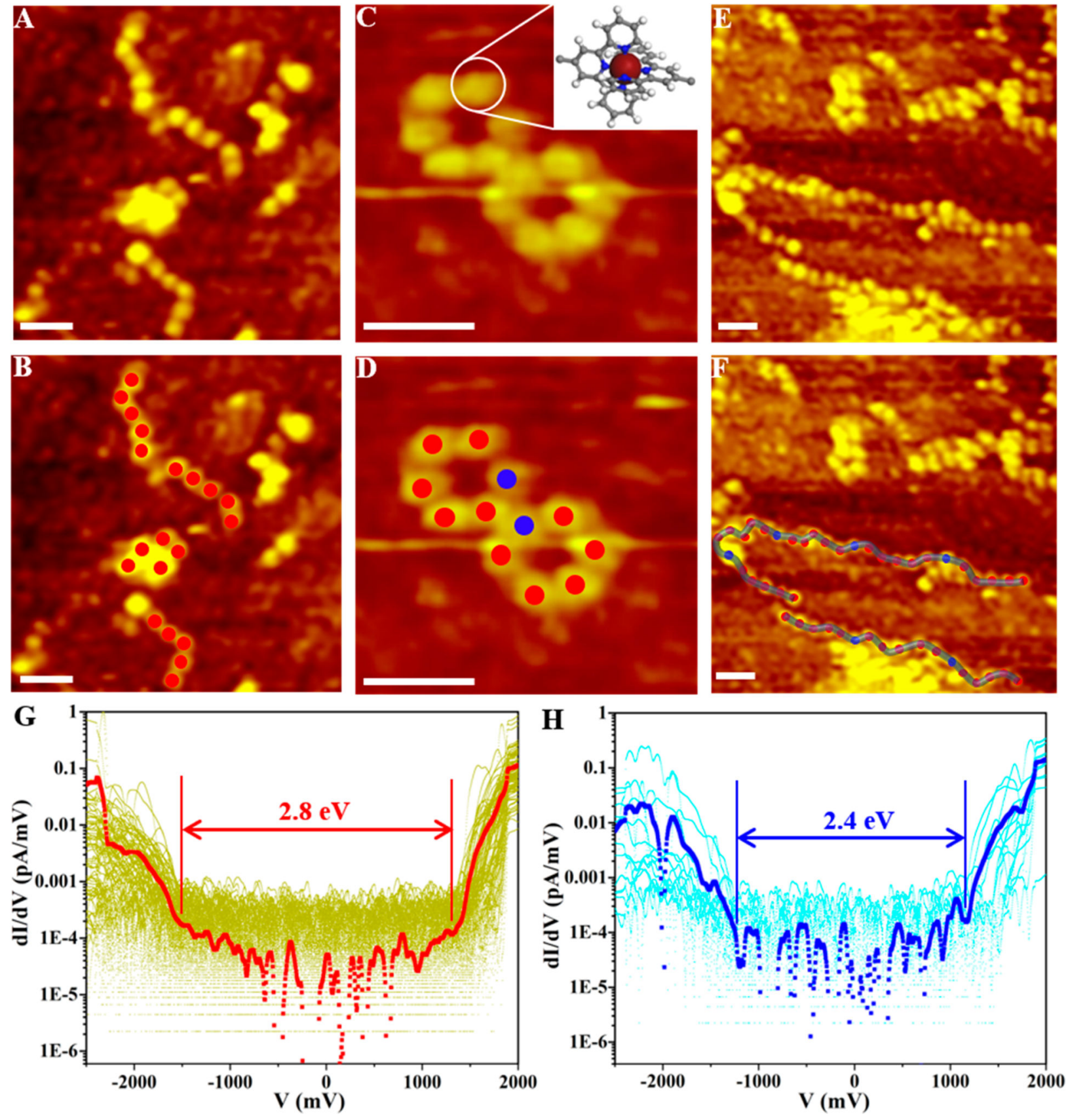

Figure 4.

(A) STM image of Hex-P on the supporting Ag(111) surface. (B) STM image of Hex-P with STS data acquisition locations on $\langle$ tpy-Ru(II)-tpy $\rangle$ unit shown in red. (C) STM image of Hex-P-C. (D) STS profiling of Hex-P-C with $\langle$ tpy-Ru(II)-tpy $\rangle$ unit in red and $\langle$ tpy-Fe(II)tpy $\rangle$ unit in blue. (E) STM image of Hex-P-L. (F) STS profiling of Hex-P-L with 〈tpy$\mathrm{Ru}$ (II)-tpy $\rangle$ unit in red and 〈tpy-Fe(II)-tpy $\rangle$ unit in blue. The blue line in the inset represents the polymer chain proposed by 〈tpy-metal(II)-tpy $\rangle$ units. d $I / d V-V$ results of STS of (G) $\mathrm{Ru}(\mathrm{II})(\mathrm{red})$ and (H) Fe(II) (blue) correspond to different electronic features in (D) and (F). Scale bar: $10 \mathrm{~nm}$. 

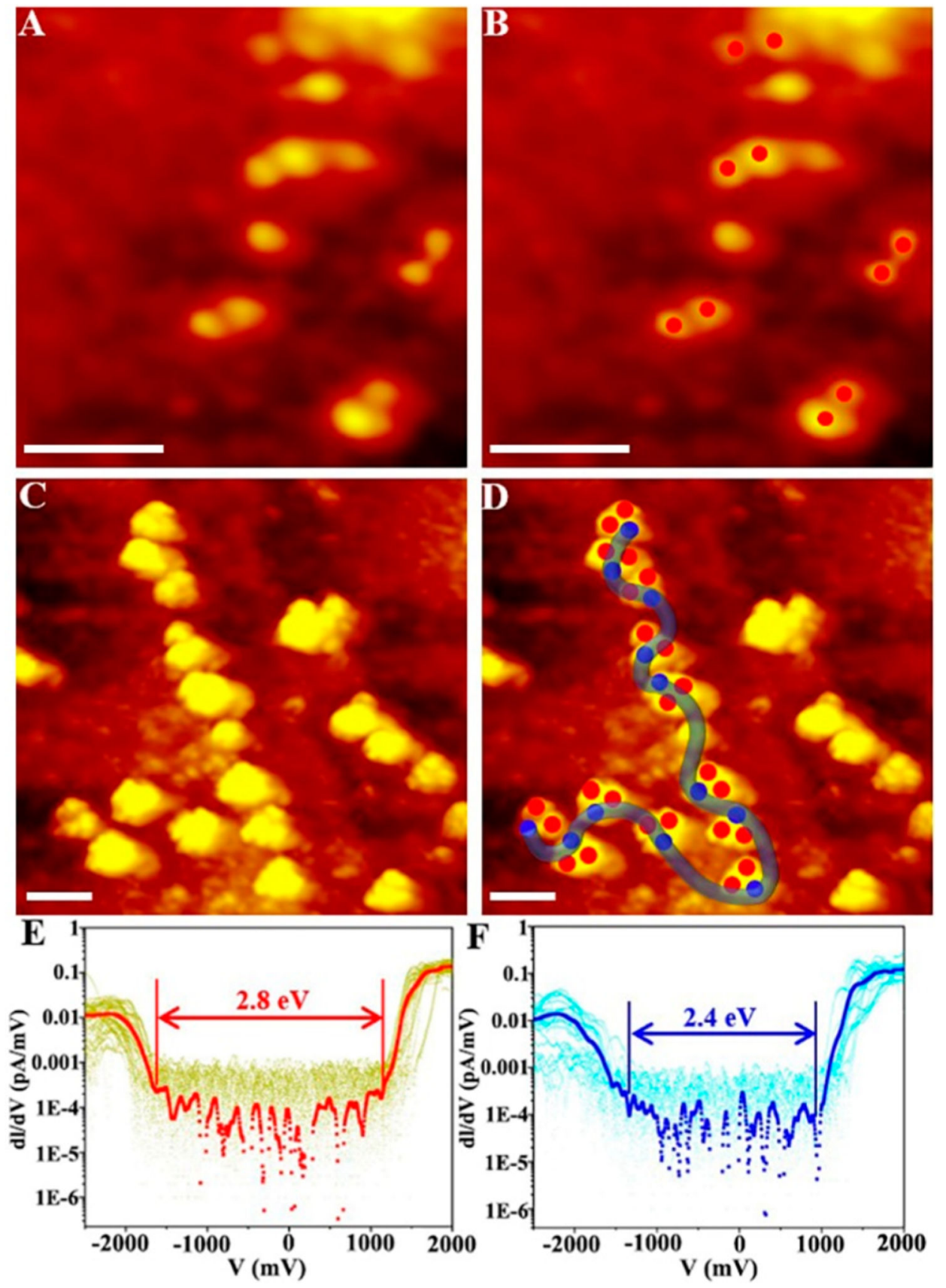

Figure 5.

(A) STM image of Tri-P on the supporting Ag(111) surface. (B) STS profiling Tri-P with the $\langle$ tpy-Ru(II)-tpy $\rangle$ unit in red. (C) STM image of Tri-P-C. (D) STS profiling of Tri-P-C with the $\langle$ tpy-Ru(II)-tpy $\rangle$ unit in red and the $\langle$ tpy-Fe(II)-tpy $\rangle$ unit in blue. The blue line in the inset represents the polymer chain proposed by $\langle$ tpy-Fe(II)-tpy $\rangle$ units. $\mathrm{d} / \mathrm{d} V-V$ results of STS of (E) Ru(II) (red) and (F) Fe(II) (blue) correspond to different electronic features in (D). Scale bar: $5 \mathrm{~nm}$. 
A

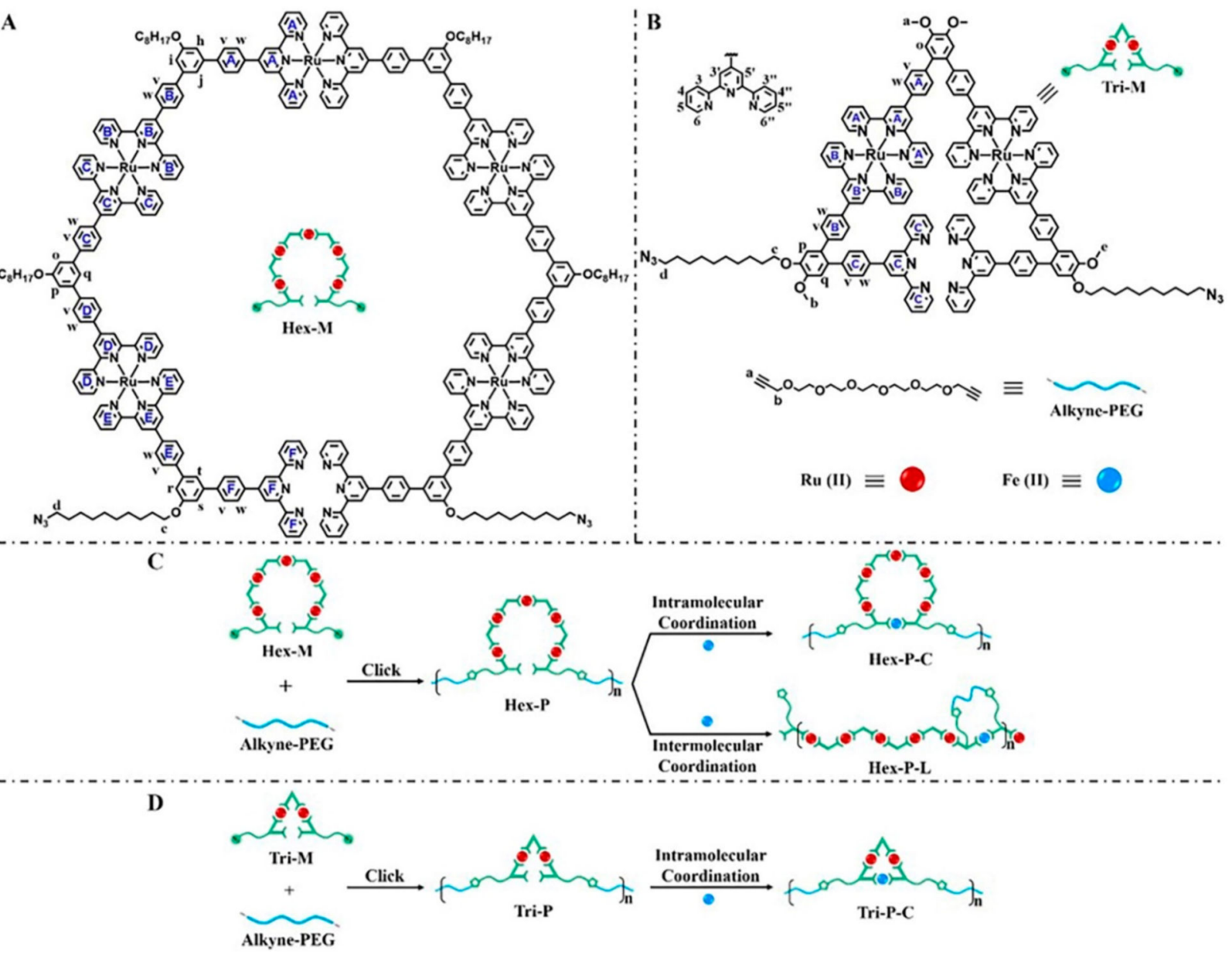

Scheme 1.

Monomers (A, Hex-M; B, Tri-M and Alkyne-PEG) and Their Corresponding

Metallopolymers with 2D Hexameric (C) and Trimeric (D) Supramolecules as Repeat Units 